\title{
The use of the PN-EN 62305-2 standard to the risk assessment of losses in the equipped object in station- devices of the railway traffic controlling
}

\author{
Zofia Wróbel ${ }^{1, *}$ \\ ${ }^{1}$ PKP Polish Railway Lines JSC, Railway Lines Establishment in Rzeszów, ul. St. Batorego 24, 35-005, Rzeszów, Poland
}

\begin{abstract}
The valuation of the risk of losses makes easy the correct estimation of resulted threats as a result of atmospheric discharges and harms connected to them. Qualifying the need of lightning protection use for the object, we ought to take into account the risk $\mathrm{R}$ for the object and for the public services devices. In every case of examining risks we ought to fulfill: the identification of components RX forming the risk, counting the identified components of the risk RX, the entire risk R, identify the tolerated risk RT and compare the risk $\mathrm{R}$ with the tolerated value RT. As a result of such analysis we can come to a decision about the use of protection resources. In the report was realized the risk analysis of devices damages for a chosen object - the signal box with installed station - relaying devices of the railway traffic controlling with a computer adjustable control panel. From the realized analysis results that DEHN Risk Tool is a useful tool for the risk analysis of lightning losses in buildings, making possible the improvement of the calculations process, especially in the range of the choice of proper protection resources.
\end{abstract}

\section{Introduction}

The object damage risk analysis as atmospheric discharges and damages connected to them result, with regard to the random occurrence, are difficult. Therefore the decision about necessity and effectivity of resources usage of the lightning and surge protection and the choice of the efficient protection method, should be preceded by the risk valuation due to statics damages. The report presents the risk analysis of the railway traffic devices damages due to statics for the chosen object - a section inspector auty room with installed computer devices of controlling the railway traffic (rtc) and in the risk analysis, a fragment of the track section in which statics appeared, was taken into account. The risk results analyses was obtained by the chosen software DEHN Risk Tool according to the standard EN 62305 - 2:2008. Protection against lightning. - Part 2: Risk management., were represented [1].

\section{The risk of lightning losses}

The risk $\mathrm{R}$ is defined (according to the standard PN-EN 62305-2:2008 pt. 3.1 .31 [1]) as the probable average value of one year's loss (people and goods). In consequence with the lightning influence, related to the object entire value (people and goods) subjected to the protection and the risk analysis give the threat estimation appears in consequence with earth lightning discharges in the object or the service - device. So it takes into account not only the threat of lively creatures and material losses due to the direct lightning stroke, but also the earth nearby discharges influence[2] and the influence of these discharges on the building installations, or connected to it devices in connections led and induced form, is also significant $[3,4]$. On the ground of the performed risk analysis we can come to a decision about the protection resources use in order to minimalize losses in the object or the service - device, so the analysis performing gives the possibility of the protection resources selection that best fit the given object type, its equipments and the way it is used.

The risk assessment also makes possible the qualification of the proper lightning protection level for the object (LPL - Lightning Protection Level) and the complex conception creation of the protection before LEMP (Lightning Electromagnetic Impulse) with the use of shielding. In the performed analysis, the chosen object was a Signal box in Łancut ( $\mathrm{Ln}$ ) along with the attached computer rtc devices and the: feeding line, mast, two telephone lines, three railway automatic level crossings and two signals at the farthest point $[5,6,7]$.

\footnotetext{
$\overline{{ }^{*} \text { Corresponding author: zwrobel@prz.edu.pl }}$
} 


\section{The object description and its environment parameters}

In the delimitation of the risk (PN EN 62305-2:2008

[1]) an essential parameter is the density of lightning discharges to-earth $\mathrm{Ng}$. It determines the number of direct lightning discharges to-earth by $\mathrm{km}^{2}$ a year. For areas, where an object is found - a signal box $\mathrm{Ln}$ (Fig. 1) according to lightning discharges to-earth density maps, the value $\mathrm{Ng}$ carries out 2.7 of lightning discharges by $\mathrm{km}^{2}$ a year [8].

The object measurements in an essential way decide about the direct lightning stroke threat, and basing on them collecting areas for direct and indirect lightning strokes are qualified. For the Signal box $\mathrm{En}$ the following measurements were accepted: length $-L_{\mathrm{b}}$ : $14 \mathrm{~m}$, width $-W_{\mathrm{b}}: 10 \mathrm{~m}$, height $-H_{\mathrm{b}}: 8 \mathrm{~m}$ and the object highest point $-H_{\mathrm{pb}}: 16 \mathrm{~m}$. For given above object measurements, the following collecting areas were calculated:

- direct discharges: $7238 \mathrm{~m}^{2}$,

- indirect discharges (nearby the object): $208489 \mathrm{~m}^{2}$.

A factor defining the number of possible direct and indirect lightning strokes is the environment surrounding the object. The relative position of the signal box is definite by the coefficient $C_{\mathrm{db}}$ which its value carries out 1 . For the lightning discharges to-earth density, considering the size and environment of the object, we ought to expect the following frequencies:

- direct lightning strokes into the object: $N_{\mathrm{D}}=0.0049$

strokes / year,

- indirect strokes nearby the object: $N_{\mathrm{M}}=0.558$

strokes/ year.

The risk analysis performed by DEHN Risk Tool [9].

The programme is adapted to appoint the risk for different countries, including Poland according to the standard PN-EN 62305-2:2008. Protection against lighting Part 2. Risk Management [1].

\section{The analysed object lightning protection zones}

The zoning can be made taking into account such criteria as: the kind of the ground or floors, fire-proof barriers, spatial shielding, the internal systems arrangement, existing or expecting protection resources losses. For the analysis, the object - a signal box $€ n$ that was divided to the following lightning protection zones (LPZ) i.e. zones for which the lightning electromagnetic environment was qualified. Limits of the zone LPZ are not always physical limits of the objects (eg. walls, floor and ceiling) [10]:

- LPZ 0B - object protected against an indirect stroke results:

Z1-outside the building (signal box),

$\mathrm{Z} 2$-the aerial mast.

- LPZ 1 - the internal zone of the protected object:

Z3 - section inspector auty room,

Z4 - the repair workshop room.

- LPZ 2 - the room/device in LPZ 1 of the screen proprieties:

Z5-the relay room

Zones of the lightning protection in the standard are defined as:

LPZ $0_{\mathrm{B}}$ : Protection against the direct stroke. The threat of a part of the thunder current and its entire electromagnetic field. Other internal systems are subject to the activity of a part of the failure current.

LPZ 1: The failure current is limited by its partition and by surge protected devices (SPD) at the bounds of the zones. The electromagnetic field is dead-beat by spatial shielding.

LPZ 2...n: Current impulses are still limited by their partition and by additional SPD at the bounds of the zones. The electromagnetic field is in general dead-beat by additional spatial shielding.

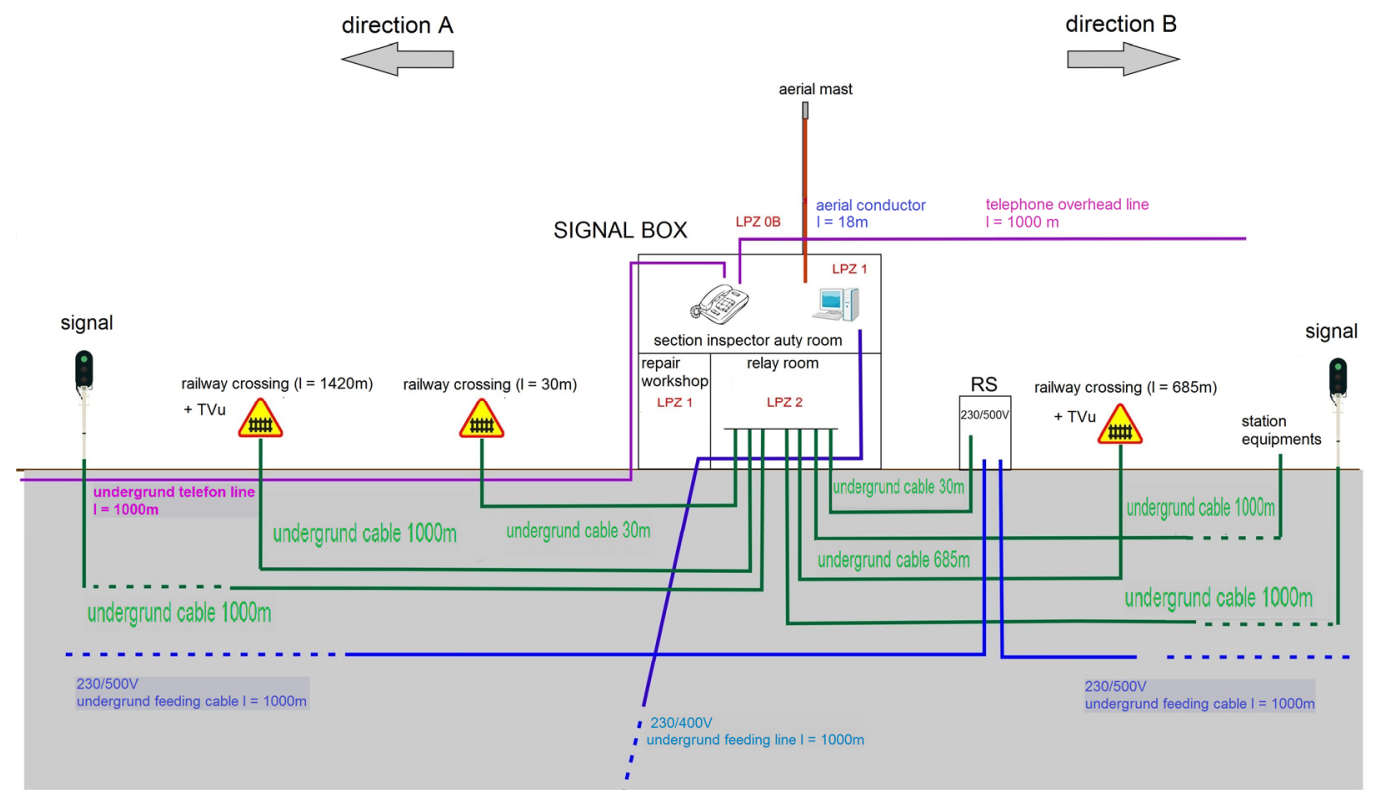

Fig. 1. Accepted to analysis object model Łn with connected devices [5] 


\section{Power supply cable}

In the analysis were taken into account the entering lines to the Signal box and going out of it [10]. Conduct pipes are not taken into account, if they are connected to the main rail earthing. If they are not earthed then they are ought to take into account in the risk analysis (requirements concerning compensations of potentials [11]). In the risk analysis for the control room building (signal box) $\mathrm{Ln}$ the following lines were taken into account:

- electric AC 230/400 V,

- telephone 1 - underground cable,

- telephone 2 - aerial line,

- signal line - railway crossing (685 m),

- the aerial conductor,

- feeding line - voltage box (RS),

- $\quad$ signal line - railway crossing $1(30 \mathrm{~m})$,

- signal line - railway crossing $2(1420 \mathrm{~m})$,

- feeding line - signal $1(10600 \mathrm{~m})$,

- feeding line - signal 2,

- feeding line - station equipments,

- feeding cable - automatic line block system $(230 / 500 \mathrm{~V})$.

For each line the following parameters were qualified: the kind of the line (overhead/underground), the length of the line (outside of the building), the environment, the connected object to the line, the type of the internal cabling (shielded/unshielded) and the least voltage holdings out equipments (the strength of receiving devices).

\subsection{The electric line AC 230/400V}

For the analysed line, was accepted that it is buried in a ground of $500 \Omega \mathrm{m}$ resistivity. It was taken into account that the object is isolated - with no other objects nearby. The environment of the object is suburban (the height of buildings is less than $10 \mathrm{~m}$ ). In the analysis was taken into account a transformer only for the service - device. The length of the line outside the building carries out $1000 \mathrm{~m}$. Areas of assembling were qualified for the electric line as:

- The assembling area of discharges into the line: $21824 \mathrm{~m}^{2}$,

- The assembling area of discharges striking nearby the line: $559017 \mathrm{~m}^{2}$.

The voltage holdings out equipment connected to the electric line AC 230/400 V, was definited for the zone Z1 and $\mathrm{Z} 3, \mathrm{Z4}$ as $2.5 \mathrm{kV}<\mathrm{Uw}<=4 \mathrm{kV}$ and for the zone $\mathrm{Z5}$ as $1.5 \mathrm{kV}<\mathrm{Uw}<=2.5 \mathrm{kV}$. The arrangement of lines in the building considering the zones: $\mathrm{Z1}, \mathrm{Z3}, \mathrm{Z4}$ and $\mathrm{Z} 5$ was accepted as unshielded cable - lack of lofting to avoid the loop.

\subsection{The underground telephone line 1}

For this line, was accepted that it is an underground telephone line at a ground resistivity of $500 \Omega \mathrm{m}$. It was taken into account that the object is isolated - lack of other objects nearby. The environment of the object is suburban (the height of buildings is less than $10 \mathrm{~m}$ ). The length of the line outside the building carries out $1000 \mathrm{~m}$. In the analysis, was taken into account a transformer only for the service device. Appointed assembling areas are:

- The assembling area of discharges into the line: $21824 \mathrm{~m}^{2}$,

- The assembling area of discharges srtiking nearby the line: $559017 \mathrm{~m}^{2}$.

The voltage holdings out equipment connected to the telephone line 1 was definited for the zone $\mathrm{Zl}$ as $1.0 \mathrm{kV}<$ $\mathrm{Uw}<=1.5 \mathrm{kV}$ and $\mathrm{Z} 3$ as $1.5 \mathrm{kV}<\mathrm{Uw}<=2.5 \mathrm{kV}$. The arrangement of lines in the building was qualified considering the zones: Z1 and Z3 as unshielded cable - lack of lofting to avoid the loop.

\subsection{The overhead telephone line 2}

For this line, was accepted that it is an overhead line at a ground resistivity of $500 \Omega \mathrm{m}$. It was taken into account that the object is isolated - lack of other objects nearby. The environment of the object is suburban (the height of buildings is less than $10 \mathrm{~m}$ ). The length of the line outside the building carries out $1000 \mathrm{~m}$. In the analysis, was taken into account a transformer only for the service - device. Appointed assembling areas are:

- The assembling area of discharges into the line: $35136 \mathrm{~m}^{2}$,

- The assembling area of discharges srtiking nearby the line: $\quad 1000000 \mathrm{~m}^{2}$.

The voltage holdings out equipment connected to the telephone line 1 was definited for the zones $\mathrm{Z} 1$ and $\mathrm{Z} 3$ as $1.0 \mathrm{kV}<\mathrm{Uw}<=1.5 \mathrm{kV}$. The arrangement of lines in the building was qualified considering the zones: $\mathrm{Z1}$ and Z3 as unshielded cable - lack of lofting to avoid the loop.

\subsection{Signal line - railway crossing 1}

The line was marked as buried in a ground of the resistivity $500 \Omega \mathrm{m}$. It was taken into account that the object is isolated - lack of other objects nearby. The environment of the object is country-side (the height of buildings is less than $10 \mathrm{~m}$ ) and in the analysis, was taken into account a transformer only for the service - device. The length of the line outside the building carries out $685 \mathrm{~m}$. Basing on this the following assembling areas were qualified for the line:

- The assembling area of discharges into the line: $23796 \mathrm{~m}^{2}$,

- The assembling area of discharges striking nearby the line: $685000 \mathrm{~m}^{2}$.

The voltage holdings out equipment connected to signal ride line 1 , was definited for the zone $\mathrm{Z} 1$ as $1.0 \mathrm{kV}<\mathrm{Uw}$ $<=1.5 \mathrm{kV}$. The arrangement of lines in the building was qualified considering the zone $\mathrm{Z} 1$ as unshielded cable - lack of lofting to avoid the loop.

\subsection{The aerial conductor}

For this line, was accepted that is an overhead line at a ground resistivity of $500 \Omega \mathrm{m}$. It was taken into account that the object is isolated - lack of other objects nearby. The environment of the object is suburban (the height of 
buildings is less than $10 \mathrm{~m}$ ) and in the analysis, was taken into account a transformer only for the service - device. The length of the line outside the building carries out $18 \mathrm{~m}$. The appointed assembling areas are:

- The assembling area of discharges into the line: $0 \mathrm{~m}^{2}$.

- The assembling area of discharges striking nearby the line: $18000 \mathrm{~m}^{2}$.

The voltage holdings out equipment connected to the aerial conductor, was definited for the zones $\mathrm{Z} 2$ and $\mathrm{Z} 3$ as $1.0 \mathrm{kV}$ $<\mathrm{Uw}<=1.5 \mathrm{kV}$.and the arrangement of lines in the building for the aerial conductor was qualified considering the zones: Z2 and Z3 as unshielded cable - lack of lofting to avoid the loop.

\subsection{Feeding line - railway crossing 2 and feeding line - voltage box (RS)}

The line was marked as buried in a ground of the resistivity $500 \Omega \mathrm{m}$. It was taken into account that the object is isolated - lack of other objects nearby. The environment of the object is suburban (the height of buildings is less than $10 \mathrm{~m}$ ) and in the analysis, was taken into account a transformer only for the service - device. The length of the line outside the building carries out $30 \mathrm{~m}$. Basing on this the following assembling areas were qualified for the line:

- The assembling area of discharges into the line: $134 \mathrm{~m}^{2}$.

- The assembling area of discharges striking nearby the line: $16771 \mathrm{~m}^{2}$.

The voltage holdings out equipment connected to signal ride line 1, was definited for the zones $\mathrm{Z1}$ and $\mathrm{Z} 5$ as $1.0 \mathrm{kV}$ $<\mathrm{Uw}<=1.5 \mathrm{kV}$. The arrangement of lines in the building was qualified considering the zones: $\mathrm{Z1}$ and $\mathrm{Z5}$ as unshielded cable - lack of lofting to avoid the loop.

\subsection{Feeding line - railway crossing 3 and feeding line - station equipments}

The line was marked as buried in a ground of the resistivity $500 \Omega \mathrm{m}$. It was taken into account that the object is isolated - lack of other objects nearby. The environment of the object is country-side (the height of buildings is less than $10 \mathrm{~m}$ ) and in the analysis, was taken into account a transformer only for the service - device. The length of the line outside the building carries out $1420 \mathrm{~m}$. Basing on this the following assembling areas were qualified for the line:

- The assembling area of discharges into the line: $21824 \mathrm{~m}^{2}$,

- The assembling area of discharges striking nearby the line: $559017 \mathrm{~m}^{2}$.

The voltage holdings out equipment connected to signal ride line 1, was definited for the zones $\mathrm{Z1}$ and $\mathrm{Z5}$ as $1.0 \mathrm{kV}$ $<\mathrm{Uw}<=1.5 \mathrm{kV}$. The arrangement of lines in the building was qualified considering the Z1 and Z5 as unshielded cable - lack of lofting to avoid the loop.

\subsection{The line signal - signal 1 and 2}

For these lines was accepted that they are lines buried in a ground of the resistivity $500 \Omega \mathrm{m}$. Each of the lines considered as an isolated object - lack of other objects nearby. The environment of the object is country-side and in the analysis was taken into account a transformer only for the service - device. The length of the line outside the building carries out $1000 \mathrm{~m}$. The assembling areas carry out

- The assembling area of discharges into the line: $21824 \mathrm{~m}^{2}$,

- The assembling area of discharges striking nearby the line: $559017 \mathrm{~m}^{2}$.

The voltage holdings out equipment connected to the signal line was definited for the zones $\mathrm{Z1}$ and $\mathrm{Z} 5$ as $1.0 \mathrm{kV}<\mathrm{Uw}$ $<=1.5 \mathrm{kV}$. The arrangement of lines in the building for signal line - signals 1 and 2 was qualified considering the zones: Z1 and Z5 as unshielded cable - lack of lofting to avoid the loop.

\subsection{Feeding line - automatic line block system (230/500 V)}

For these lines was accepted that they are lines buried in a ground of the resistivity $500 \Omega \mathrm{m}$ and each line was considered as an isolated object - lack of other objects nearby. The environment of the object is country-side.and in the analysis was taken into account a transformer only for the service - device. The length of the line outside the building carries out $1000 \mathrm{~m}$. The assembling areas carry out

- The assembling area of discharges into the line: $21824 \mathrm{~m}^{2}$,

- The assembling area of discharges striking nearby the line: $559017 \mathrm{~m}^{2}$.

The voltage holdings out equipment connected to the signal line - feeding cable automatic electric block system was definited for the zones $\mathrm{Z1}$ and $\mathrm{Z} 5$ as $1.0 \mathrm{kV}<\mathrm{Uw}<=$ $1.5 \mathrm{kV}$ and the arrangement of lines in the building for signal line - signals 1 and 2 was qualified considering the zones: Z1 and Z5 as unshielded cable - lack of lofting to avoid the loop.

\section{The fire risk}

The fire risk determines an important criterion at qualifying the class of the lightning protection (LPS - lightning protection system) for the building. The gradation of the fire risk is based on values of specific fire load and it is defined in analysed standard [9]. The fire load is fixed by expert of fire precautions or defined after consultation with the owner of the building or with his insurance - firm. The fire risk for the given object $Ł n$ was qualified as a usual (common) one. Considering the number of persons being in the object $\mathrm{Ln}$ for zones $\mathrm{Z} 1$ and $\mathrm{Z} 2$ was assumed the lack of a special threat, and for zones Z3, Z4 and Z5 was fixed for a low level of panic (for no more than 100 persons).

\section{External spatial shielding}

Shielding spatial extinguishes the electromagnetic field inside the building, that appears at hits of the thunder into the building or close to it. This causes limitation of inducing surges in internal installations. This way is created 
a net of equalizing connections in which are taken into account all conductible parts of the building and internal systems. External or internal spatial shielding contains only the shielding part of the building structure. In the analysis was accepted the lack of shielding.

\section{The valuation of the risk and the choice of protection resources}

In the analysis, the risks R1, R2 and R4 were marked. For the risk R1 of the loss of human life for persons outside and inside the signal object $\mathrm{n}$ was fixed so that in the case of no-protection, the tolerated risk RT carries out 1E-05, and appointed in DEHN Risk Tool the risk R1 carries out 2.23E-06. With using protection, the risk R1 dropped to the value $9.5 \mathrm{E}-07$ which is considerably less than the tolerated value. The risk R2 (the loss of public service), for the signal box $\mathrm{n}$ was fixed so that the tolerated risk RT carries out 1E-03. The appointed risk R2 carries out 1.32E-02 with noprotection that is to say the admissible level was 12.2 times exceeded. Whereas at using protection resources the risk R2 dropped to the value 2.7E-04.

The risk analysis $\mathrm{R} 4$ is performed to reduce the economic losses value taking into account the present and the target state. The result of these calculations is the cost of chosen protection resources with reference to the building and economic reason values. In marking were taken into account the following parameters: $\mathrm{i}$ - the interest rate: 1.1 $\%$, at - the amortization time: 10 years, a - the depreciation rate $10 \%$ and $\mathrm{m}$ - exploitation rate $1.1 \%$. To qualify the costs of the building, were taken into account: one year's cost of the building $\left(\mathrm{C}_{\mathrm{B}}\right)$ carrying out 23800 zloty, the content cost $\left(\mathrm{C}_{\mathrm{C}}\right) 2618697$ zloty and the cost of systems in the object $\left(\mathrm{C}_{\mathrm{S}}\right) 130000$ zloty. Single costs of protection resources was accepted as 10000 zloty. As a result of the risk R4 estimation was received the entire cost of losses on account of the thunder in the case of the lack of protection resources $\mathrm{C}_{\mathrm{L}}$ : 17412 zloty/year. The cost of deciduous losses $\mathrm{C}_{\mathrm{RL}}$ on account of the thunder in the case of the presence of chosen protection resources carries out 437.7 zloty/year. The yearly cost of chosen protection resources CPM in the accepted amortization period of 10 years carries out 0 zloty/year. Yearly savings with using chosen protection resources carry out 16974.6 zloty/year. So the use of chosen protection resources is well-founded economically.

Reducing the existing risk to an accepted level is obtained through the selection of suitable protection means. The selection of these resources determines a part of the risk management for the signal box $Ł n$ and is proper only with reference to this object. In the final part of the programme printout were placed protection resources, that should be used to assure a proper protection for the object with a zoning $[5,8]$.

\section{Conclusions}

From the performed analysis results that every used resource of the protection has an influence on its protection level. Properly well-chosen surge protection devices should be conditioned on the least profitable of connection arrangements, that can appear in given installation. Especially important is the use of suitable protection resources, including the protection of non-resident lines led to the control room (signal box) building and joint to computer devices. These circuits are most subject to damage due to surges of atmospherical origin.

The aim of further analyses is the realization of the risk assessment of lightning losses, in the new edition of the standard PN-EN 62305-2:2012 in which were introduced several of essential changes with relation to the edition from 2008r. Interesting will be so, how the introduced changes can shift themselves on results and the risk analysis assessments of lightning losses in specific cases of buildings, and the choice of required level and protection resources against the lightning electromagnetic impulse (LEMP).

\section{References}

1. PN-EN 62305 Part 2, Protection against lightning Risk Management. (2008) [In English]

2. A. Kern, G. Dikta: 29th2014 International Conference on Lightning Protection (ICLP), Uppsala, Sweden, 7a6-1 - 7a-6-14 (2008) [In Polish]

3. Z. Wróbel, R. Ziemba, M. Gamracki, TTS Technika Transportu Szynowego, 11, pp. 31-34 (2008) [In Polish]

4. Z. Wróbel, Technical Transactions Electrical Engineering ISSUE 1-E (2), 113 pp. 163-176. (Cracov, Poland, 2016) [In English]

5. Materials of PKP Polish Railway Lines JSC (C), [In Polish]

6. PN-EN 62305 Part 3, Protection against lightning. Physical damage to structures and life hazard. (2011) [In English]

7. PN-EN 62305 Part 4, Electrical and electronic systems within structures. (2011) [In English]

8. M. Łoboda, Scientific Research Papers, Rzeszów University of Technology, Electrotechnics, No. 33, (2013), [In Polish]

9. DEHNsupport Toolbox. Help for the designer. [In Polish]

10. PN-EN 62305- Part 1, Protection against lightning. General principles. (2012) [In English]

11. Z. Wróbel, XVII National Scientific Conference of Electric Traction, SEMTRAK 2016, Zakopane, pp. $156 \div 169$. (2016) [In Polish]. 